\title{
Barrett Esophagus-Indefinite for Dysplasia
}

National Cancer Institute

\section{Source}

National Cancer Institute. Barrett Esophagus-Indefinite for Dysplasia. NCI Thesaurus.

Code C95615.

A finding indicating the presence of Barrett esophagus in which technical reasons make the interpretation of atypia difficult, atypia is present but it is not quite to the level of dysplasia, or atypia is present at the bases of the crypts but does not reach the surface of the crypts. 